\title{
Vorwort zur dritten Auflage
}

Die dritte Auflage ist gegen die zweite noch mehr verändert als diese gegen die erste; bildete bei ihr die geschichtliche Darlegung den Grundstock, den die sachliche Erörterung nur umsäumte, so ist diese in der zweiten Auflage weit selbständiger geworden und hat in der dritten die volle Herrschaft erlangt; das Buch ist nun vor allem ein Ausdruck einer eigentümlichen philosophischen Gesamtüberzeugung und will als solcher gewürdigt sein. Das muBte auch die Darstellung wesentlich verändern, das verlangte namentlich eine präzisere Anordnung und Einteilung des Stoffes bis in die einzelnen Abschnitte hinein.

Den Grundgedanken der früheren Behandlungen: die Verknüpfung von Historischem und Sachlichem einerseits, die Zerlegung in einzelne Abschnitte andererseits glaubte ich dabei festhalten zu können. $\mathrm{DaB}$ das Geschichtliche mir mehr ist als ein Gegenstand gelehrter Beschäftigung, da $\beta$ es, freilich unter bestimmten Voraussetzungen, zur Erhöhung der eignen Arbeit kräftig beizutragen vermag, dafür kämpft das Buch ebenso als Ganzes wie in besonderen Erörterungen, die sich hier nicht vorwegnehmen lassen. Das Ausgehen von einzelnen Problemen aber gewährte den Vorteil greifbarer Angriffspunkte, von denen sich rasch $\mathrm{zu}$ irgendwelcher Entscheidung vordringen ließ. Allerdings verblieb dabei der Mißstand, daß das Ganze der Überzeugung nicht als solches volle Rechenschaft geben und sich in einem fortlaufenden Zusammenhange darlegen kann. 
Dieser Mangel sei bereitwillig zugestanden, er ist zu eng mit dieser Behandlungsweise verbunden, als daß sich ihm hier abhelfen ließe. Gewisse Ergänzungen bieten in dieser Hinsicht meine früheren Bücher, die größte Lücke liegt in dem Mangel einer genügenden erkenntnistheoretischen Fundamentierung, mein nächstes Buch wird einer prinzipiellen Erörterung dieses Problems gewidmet sein.

Mehr noch als die Art der Behandlung aber ist es eine durchgehende Grundüberzeugung, welche die verschiedenen Auflagen zusammenhält, die Überzeugung von der Unsicherheit des Bodens, auf dem unser ganzes Kulturleben und mit ihm auch unsere wissenschaftliche Arbeit steht, die Überzeugung, $\mathrm{da} B$ dieses Leben nicht nur einzelne Probleme in Hülle und Fülle enthalte, sondern daß es auch als Ganzes einer energischen Revision und einer gründlichen Erneuerung bedürfe. Am Streben danach aber schien mir auch die Philosophie sich beteiligen zu müssen, ja sie besonders schien hier zu eifriger Mitarbeit berufen. Das brachte mich in Gegensatz zum Hauptzuge der heutigen deutschen Philosophie, der seine wissenschaftliche Arbeit unbeirrt durch jene Fragen und Zweifel ruhig fortführen zu können meint. Wie viel Wertvolles diese Arbeit, namentlich in der genaueren Durchbildung der einzelnen Erkenntnisgebiete, geleistet hat und weiter leistet, das sei freudig und dankbar anerkannt. Aber zugleich sei auch auf dem Rechte und der Notwendigkeit jenes allgemeineren Problems mit aller Entschiedenheit bestanden; wir werden uns in der Arbeit dafür in keiner Weise durch die Sorge um die Stellung anderer dazu beirren lassen, sondern lediglich und allein der inneren Notwendigkeit der Sache vertrauen.

Aber es sprechen neuerdings auch Zeichen in Hülle und Fülle dafür, daß weitere Kreise den Problemen, für die wir eintreten, ihre Teilnahme zuwenden. Die inneren Verwicklungen unserer Kultur, ja unserer gesamten geistigen Lage werden 
immer augenscheinlicher, mehr und mehr empfinden wir darin schwere Unwahrheiten, Phrasen, wo wir Wirklichkeiten, Steine, wo wir Brot suchten. Nun steht dabei das Glück und der Sinn unseres eignen Daseins auf dem Spiele; so erhebt sich immer dringender das Verlangen nach Klärung wie nach Befestigung, so wird auch die Philosophie immer zwingender zur Arbeit an diesen Lebensfragen aufgerufen. Neue Wogen des Lebens steigen auf, neue Stimmungen ergreifen die Gemüter und heißen sie neue Ziele suchen.

Diese inneren Wandlungen haben auch meinen Büchern mehr und mehr Freunde zugeführt und mir das Bewußtsein eines engen geistigen Kontaktes mit der Zeit gegeben, das ich früher nicht haben konnte. Mit besonderer Freude begrüße ich die unerwartet rasch wachsende Teilnahme des aufsteigenden jüngeren Geschlechts; möchte solche Teilnahme auch diesem Buche zugute kommen, und möchte sie namentlich zu einer Weiterführung der hier bloß entworfenen und sicherlich oft sehr unvollkommen behandelten Probleme wirken. Denn was uns gemeinsam vorschwebt, ist schließlich nichts geringeres als die Idee eines neuen Menschen und einer neuen Kultur; nur ein Zusammenschluß der Kräfte, nur eine Überwindung alles bloß Individuellen, nur das Entstehen einer durchgehenden Bewegung kann uns bei einer so gewaltigen Frage weiterbringen.

Jena, im Februar 1904.

Rudolf Eucken 